\title{
Multi-scenario rockfall hazard assessment using LiDAR data and GIS
}

\begin{abstract}
Transportation corridors that pass through mountainous or hilly areas are prone to rockfall hazard. Rockfall incidents in such areas can cause human fatalities and damage to properties in addition to transportation interruptions. In Malaysia, the North-South Expressway is the most significant expressway that operates as the backbone of the peninsula. A portion of this expressway in Jelapang was chosen as the site of rockfall hazard assessment in multiple scenarios. Light detection and ranging techniques are indispensable in capturing highresolution digital elevation models related to geohazard studies. An airborne laser scanner was used to create a high-density point cloud of the study area. The use of 3D rockfall process modeling in combination with geographic information system (GIS) is a beneficial tool in rockfall hazard studies. In this study, a 3D rockfall model integrated into GIS was used to derive rockfall trajectories and velocity associated with them in multiple scenarios based on a range of mechanical parameter values (coefficients of restitution and friction angle). Rockfall characteristics in terms of frequency, height, and energy were determined through raster modeling. Analytic hierarchy process (AHP) was used to compute the weight of each rockfall characteristic raster that affects rockfall hazard. A spatial model that considers rockfall characteristics was conducted to produce a rockfall hazard map. Moreover, a barrier location was proposed to eliminate rockfall hazard. As a result, rockfall trajectories and their characteristics were derived. The result of AHP shows that rockfall hazard was significantly influenced by rockfall energy and then by frequency and height. The areas at risk were delineated and the hazard percentage along the expressway was observed and demonstrated. The result also shows that with increasing mechanical parameter values, the rockfall trajectories and their characteristics, and consequently rockfall hazard, were increased. In addition, the suggested barrier effectively restrained most of the rockfall trajectories and eliminated the hazard along the expressway. This study can serve not only as a guide for a comprehensive investigation of rockfall hazard but also as a reference that decision makers can use in designing a risk mitigation method. Furthermore, this study is applicable in any rockfall study, especially in situations where mechanical parameters have no specific values.
\end{abstract}

Keyword: Rockfall hazard; LiDAR; Modelling; Remote sensing; GIS 